\title{
Solid State NMR Characterization and Adsorption Properties of Lignocellulose-Clinoptilolite Composites Prepared with Siloxanes Coupling Agents
}

\author{
R.M.K. Vala ${ }^{\mathrm{a}, \mathrm{c}, \boldsymbol{}}$, L. Tichagwa ${ }^{\mathrm{a}}$, H. Pasch ${ }^{\mathrm{b}}$ and E.D. Dikio ${ }^{\mathrm{c}}$ \\ ${ }^{a}$ Formerly, Department of Pure and Applied Chemistry, University of Fort Hare, Private Bag X1314, Alice, 5700, South Africa. \\ ${ }^{b}$ Deparment of Chemistry and Polymer Science, University of Stellenbosch, Private Bag X1, Matieland, 7602, Stellenbosch, South Africa. \\ ${ }^{c}$ Deparment of Chemistry, Applied Chemistry and Nanoscience Laboratory, Vaal University of Technology, \\ P.O. Box X021, Vanderbijlpark, 1900, South Africa.
}

Received 15 July 2014, revised 16 February 2015, accepted 26 February 2015.

\begin{abstract}
This study reports the preparation of lignocellulose-clinoptilolite composites by means of N-terminated siloxanes as coupling agents, after acid hydrolysis. Reactions were carried out in the presence of dibutyltin dilaurate as catalyst by reacting lignocellulose modified with the coupling agents and clinoptilolite at $140^{\circ} \mathrm{C}$ in DMF under nitrogen atmosphere. The light in weight and fluffy composites obtained were characterized by FT-IR, XRD, TGA, SEM and Solid State NMR. Results depicted possible chemical interactions between the two materials (lignocellulose and clinoptilolite). Used as adsorbents, the composites showed to be good candidates for the removal of used motor oil from aqueous solution, with up to $92 \mathrm{mg} \mathrm{g}^{-1}$ of chemical oxygen demand removed.
\end{abstract}

KEYWORDS

Lignocellulose, clinoptilolite, chemical modification, composites, solid state NMR, used motor oil.

\section{Introduction}

Over the last few years, researchers have been investigating the use of natural fibres as constituents of composite materials. Such investigation has increased because of the relative low cost, ability to be recycled, and the fact that these materials can compete well in terms of strength per weight. ${ }^{1-4}$ Also, the composites are environmentally friendly, fully degradable and sustainable, and at the end of their life spans, can be easily disposed or composted without harming the environment. ${ }^{2,3}$

Developed to produce materials with performance that combines the positive attributes of each component for various applications, the preparation of composites is challenged at the interface between the filler and the matrix, ${ }^{5}$ causing problems, such as poor compatibility, insufficient stress transfer, and high water uptake. Organic-inorganic composites have interesting mechanical, optical, electrical and thermal properties compared to those of the starting materials; ${ }^{6}$ however, the differences in the individual intermolecular interaction forces, the interfacial incompatibility between the materials often cause failures in the preparation of composites to achieve homogeneous mixture. ${ }^{78}$ Moreover, if natural fibres are used as matrix, an improvement in filler-matrix adhesion is usually achieved by filler surface or matrix (fibres) modifications, addition of compatibilizers or coupling agents. ${ }^{8}$ Therefore, compatibility of components of composites is one of the major challenges encountered which necessitate the use of a bridge to bring materials together.

Lignocellulose is used in composites for being abundant, non-hazardous and of relative low cost in addition to it being eco-friendly, biodegradable, renewable, of low density. It has gained widespread use in the plastics, automobile, packaging industries, ${ }^{9-11}$ and many point it out as adsorbent and thermoplastics material. ${ }^{12-15}$

Although some authors reported the preparation and use * To whom correspondence should be addressed. E-mail: mavularemy@gmail.com of lignocellulose-zeolite composites, most of them have used cellulose, instead of the lignocellulose complex. Fisher. ${ }^{16}$ used polyethylene, polypropylene and poly(vinylchloride) as coupling agents to prepare wood-zeolite composites. Most of zeolites composites have been prepared either with synthetic polymers such as organosiloxanes ${ }^{17}$ or activated carbon-derived lignocellulose. ${ }^{18}$ As for lignocellulose-clinoptilolite composites, very little was found in the literature probably because of two reasons: (1) the weak interaction between the two materials and the uneven distribution of zeolite on the lignocellulose surface as reported by Mintova and Valtchev ${ }^{19}$ and (2) their individual efficiency in different applications. It therefore seemed essential to investigate the preparation of lignocellulose-clinoptilolite composites and evaluate their sorptive properties towards water pollutants, such as motor oil.

Used motor oil is a harmful polluting product; its disposal should be done with environmental concerns. It was shown that biodegradation of motor oil can last for years depending on factors, such as: low numbers of microbes, insufficient oxygen or nutrient availability, temperature and water availability. ${ }^{20-22}$ Researchers ${ }^{23,24}$ have pointed out the adverse effects of used motor oil on the environment, regarding oil as capable of generating carcinogens and endocrine disrupters ${ }^{25-27}$ and interfering with respiration across gill surfaces of fishes and other animals. ${ }^{28}$ Unfortunately, routine maintenance of vehicles ends up polluting water bodies with oil, especially in developing countries. Thus, sorbent materials (cotton, milkweed, kenaf vegetable, wool fibres and clay mineral) have been tested for the removal of oil from water, ${ }^{29-35}$ giving promising results.

However, to the best of the authors' knowledge, there is no report in the literature on the preparation, solid state NMR characterization of lignocellulose-clinoptilolite composites prepared with $\mathrm{N}$-terminated siloxanes as coupling agents, and their use as adsorbents, especially for the removal of used motor 
oil. Therefore, this study presents the preparation of lignocellulose-clinoptilolite composites with siloxanes (coupling agent) and dibutyltindilaurate (catalyst). The composites (characterized by FT-IR, XRD, SEM, TGA and solid state NMR) were used as adsorbent for the removal of motor oil from aqueous solution.

\section{Experimental}

\subsection{Materials}

Siloxanes (3-aminopropyl-terminated polydimethylsiloxane, molecular weights: 1000,2600 , and $11000 \mathrm{~g} \mathrm{~mol}^{-1}$ for siloxane NH15D, NH40D, and NH130D, respectively) used as coupling agents were supplied by Wacker Chemie AG, Germany, dibutyltindilaurate (DBTDL) and dimethylformamide (DMF) by Sigma Aldrich; all were used without further modification. Kikuyu grass (Pennisetum clandestinum) was collected from gardens at the University of Fort Hare (Eastern Cape, South Africa), and used as source of lignocellulose. Clinoptilolite was obtained from Cape Bentonite (Pty) Ltd. (Heidelberg, Western Cape, South Africa). Used motor oil (collected from a garage in Alice, Eastern Cape, South Africa) was filtered (Whatman filter paper, $150 \mathrm{~mm} ø$ ) and oven-dried in an open vessel for $48 \mathrm{~h}$ at $60^{\circ} \mathrm{C}$ with frequent shaking. The properties of the oil are summarized (Table 1).

Table 1 Properties of used motor oil.

\begin{tabular}{lc}
\hline Parameter & Value \\
\hline Water content $(\mathrm{w} / \mathrm{w} \%)$ & 6.9 \\
Density $\left(\mathrm{kg} \mathrm{m}^{-3}\right)$ & 882 \\
Viscosity $(\mathrm{mPa} \cdot \mathrm{s})(\mathrm{by}$ DV-E Viscometer at $50 \mathrm{rpm})$ & 420 \\
Inorganic content $(\mathrm{w} / \mathrm{w} \%)$ & 0.5 \\
\hline
\end{tabular}

\subsection{Clinoptilolite Treatment}

Clinoptilolite was pre-treated according to the literature ${ }^{36-39}$ as follows: $20 \mathrm{~g}$ of raw clinoptilolite were ground into powder in order to pass through a $425 \mu \mathrm{m}$ U.S sieve. The powder obtained was refluxed in $\mathrm{HCl}(0.25 \mathrm{~N})$ for $6 \mathrm{~h}$ at $96^{\circ} \mathrm{C}$ in order to extract impurities. After filtration, the residue was thoroughly washed, first with cold and then with hot deionized water, until all traces of acid were removed and the $\mathrm{AgNO}_{3}$ chloride test proved negative. The purified clinoptilolite was then calcinated at $300{ }^{\circ} \mathrm{C}$ for $8 \mathrm{~h}$.

\subsection{Grass/Lignocellulosic Material Treatment}

Grass was pre-treated according to the procedure obtained from Ruiz and Ehrman ${ }^{40}$ and Palmowski and Muller. ${ }^{41}$ Soluble substances were extracted by decoction for $30 \mathrm{~min}$. The mixture was filtered and the residue thoroughly water washed until the filtrate became 'colourless'. The solid residue (lignocellulose) was oven-dried overnight at $65^{\circ} \mathrm{C}$ and then fractionated (hydrolyzed) in $\mathrm{H}_{2} \mathrm{SO}_{4}$ according to the literature ${ }^{42-45}$, prior to chemical modification.

The chemical modification of lignocellulose by siloxanes was adapted from the work of Matías ${ }^{46}$ and Le Digabe ${ }^{47}$ and carried out as follows: in a 3-neck round-bottomed flask, $10 \mathrm{~mL}$ of 3-aminopropyl-terminated polydimethylsiloxane were added to $1.5 \mathrm{~g}$ of lignocellulose in $30 \mathrm{~mL}$ of DMF and refluxed for $5 \mathrm{~h}$ at $130^{\circ} \mathrm{C}$. The reaction was carried out under $\mathrm{N}_{2}$, in the presence of $200 \mu \mathrm{L}$ of DBTDL. The product was Soxhlet extracted with $100 \mathrm{~mL}$ THF for $5 \mathrm{~h}$. The resulting materials were oven-dried overnight at $65^{\circ} \mathrm{C}$ and designated as: LNH15D (lignocellulose modified with siloxane NH15D), LNH40D (lignocellulose modified with siloxane NH40D) and LNH130D (lignocellulose modified with siloxane NH130D).

\subsection{Preparation of Lignocellulose-Clinoptilolite Composites}

Lignocellulose-clinoptilolite composites were prepared by reacting the chemically modified lignocellulose with clinoptilolite. The composites were prepared according to a procedure adapted from $\mathrm{CaO}^{48}$ as follows: required amounts of lignocellulose modified with siloxanes were added to $50 \mathrm{~mL}$ of DMF, then required amounts of clinoptilolite powder were slowly added to the mixture and stirred at room temperature for $30 \mathrm{~min}$. Temperature was then raised up to $140^{\circ} \mathrm{C}$ and stirred under $\mathrm{N}_{2}$ for $5 \mathrm{~h}$ to yield the composites. Unreacted chemicals were Soxhlet extracted from composites with $50 \mathrm{~mL}$ of THF for $5 \mathrm{~h}$ and overnight dried at $65^{\circ} \mathrm{C}$. The mass ratio of lignocellulose modified with siloxane to clinoptilolite was $2: 1$. The composites were then thoroughly washed with deionized water and overnight dried at $65^{\circ} \mathrm{C}$. The resulting composites were designated as: $\mathrm{CNH} 15 \mathrm{D}$ (composite prepared with siloxane NH15D), CNH40D (composite prepared with siloxane NH40D) and CNH130D (composite prepared with siloxane NH130D). The fibrous materials obtained were fawn in colour, spongy and fluffy.

\subsection{FT-IR, XRD, TGA and SEM Characterization}

All the materials were characterized by FTIR in a matrix of $\mathrm{KBr}$ by means of a Perkin Elmer System 2000 FTIR spectrophotometer (Perkin Elmer, Beaconsfield Bucks, England). X-ray diffraction (XRD) patterns were obtained using a Bruker D8

Advance diffractometer (Bruker, Germany) with $\mathrm{CuK} \alpha$ radiation $\left(\lambda \mathrm{K} \alpha_{1}=1.5406 \AA\right)$ at $40 \mathrm{kV}$ and $40 \mathrm{~mA}$. The thermogravimetric analysis (TGA) was evaluated on TGA-7 Perkin Elmer Pyris (heating rate of $20{ }^{\circ} \mathrm{C} \mathrm{min}-1$ at the temperature range of $20-900{ }^{\circ} \mathrm{C}$ in static atmosphere, weight of samples taken in the range of 7.6-9.8 mg). The surface morphology was examined by scanning electron microscopy (SEM) with a JEOL JSM-6390 LV scanning electron microscope (from JOEL, Tokyo, Japan), using an accelerating voltage of $15 \mathrm{kV}$.

\subsection{Experimental for ${ }^{13} \mathrm{C}$ Solid State NMR Analysis}

The solid state (SS) NMR spectra were acquired on a Varian (VNMRS WB 500 solids) static magnetic field strength: $11.7 \mathrm{~T}$ (corresponding to a proton larmor frequency of $500 \mathrm{MHz}$ ) two-channel spectrometer using $6 \mathrm{~mm}$ zirconia rotors and a $6 \mathrm{~mm}$ Chemagnetics ${ }^{\mathrm{TM}}$ T3 HX MAS probe. The ${ }^{13} \mathrm{C}\{1 \mathrm{H}\}$ cross-polarization (CP) spectrum was recorded at ambient temperature with high-power proton decoupling using a recycle delay of $5 \mathrm{~s}$ on the composite sample as well as the lignocellulose. The power parameters were optimized for the Hartmann-Hahn match; the radio frequency fields were $\mathrm{Y}_{\mathrm{C}} \mathrm{B}_{1 \mathrm{C}}=\mathrm{Y}_{\mathrm{H}} \mathrm{B}_{1 \mathrm{H}} \approx 56 \mathrm{kHz}$. The contact time for cross-polarization was $1 \mathrm{~ms}$. Magic angle spinning (MAS) was performed at $5 \mathrm{kHz}$ and adamantane was used as an external chemical shift standard where the downfield peak was referenced to $38.3 \mathrm{ppm}$. Additionally ${ }^{13} \mathrm{C}\{1 \mathrm{H}\} \mathrm{CP}$ MAS experiments with total spinning sideband suppression (TOSS) were performed.

\subsection{Experimental ${ }^{29} \mathrm{Si}$ SS NMR Analysis}

The clinoptilolite and composite samples were studied using ${ }^{29}$ Si SS NMR on a Varian spectrometer (VNMRS WB 500 solids) static magnetic field strength: $11.7 \mathrm{~T}$ (corresponding to a proton lamor frequency of $500 \mathrm{MHz}$ ) two-channel spectrometer using $6 \mathrm{~mm}$ zirconia rotors and a $6 \mathrm{~mm}$ Chemagnetics $^{-}$T3 HX MAS probe. One-pulse MAS experiments were performed at a spinning frequency of $5 \mathrm{kHz}$ using a pulse length of $5 \mu \mathrm{s}$. The spectra 
were measured under partially relaxed conditions. The power parameters of the ${ }^{29} \mathrm{Si}\{1 \mathrm{H}\} \mathrm{CP}$ MAS experiments were optimized for the Hartmann-Hahn match; the radio frequency fields were $\gamma_{\mathrm{C}} \mathrm{B}_{1 \mathrm{C}}=\gamma_{\mathrm{H}} \mathrm{B}_{1 \mathrm{H}} \approx 56 \mathrm{kHz}$. The contact time for cross-polarization was $2 \mathrm{~ms}$ and the recycle delay used was $3 \mathrm{~s}$. The ${ }^{29} \mathrm{Si}$ onepulse MAS spectra of clinop-HCl measured with and without spinning sideband suppression was conducted.

\subsection{Experimental Procedure for the Adsorption of Motor Oil}

Adsorption experiments were conducted with used motor oil (adsorbate) that was emulsified in deionized water and then used as oily wastewater as follows: a known amount (200, 400, $600,800,1000 \mathrm{mg}$ ) of oil was ultrasonicated for $20 \mathrm{~min}$ with $100 \mathrm{~mL}$ of deionized water in order to make a water emulsion in a conical flask $(500 \mathrm{~mL})$ and $0.1 \mathrm{~g}$ of adsorbent (lignocelluloseclinoptilolite composite) added to the mixture. Each mixture (oil-in-water emulsion + adsorbent) was shaken on an orbital shaker (mrc Orbital shaker) at $160 \mathrm{rpm}$. Aliquots of the mixture were collected after 5, 15, 30, 60, 180, $300 \mathrm{~min}$. The oil-in-water emulsion was filtered through a $0.45 \mu \mathrm{m}$ syringe filter after sorption experiments and taken for chemical oxygen demand (COD) measurement. Initial COD and a blank were recorded for each run. All experiments were conducted in duplicate and mean values were used in the analysis of data. COD measurements were done by means of COD Spectroquant Pharo 100 spectrophotometer (Merck) and adsorbed COD was calculated (Equation 1):

$$
\mathrm{Q}_{\mathrm{t}}=\frac{\mathrm{V}\left(\mathrm{COD}_{\mathrm{o}}-\mathrm{COD}_{\mathrm{e}}\right)}{\mathrm{m}}
$$

where $\mathrm{Q}$ is the $\mathrm{COD}$ of oil adsorbed $\left(\mathrm{mg} \mathrm{g}^{-1}\right)$ at time, $\mathrm{COD}_{\mathrm{o}}$ and COD are the initial and equilibrium CODs (in $\mathrm{mg} \mathrm{L}^{-1}$ ), is the dry mass of adsorbent (g), and is the volume of solution (l).

It is important to note that although ultrasonication was used for the oil-in-water emulsion preparation, aliquots for COD analysis before adsorption could only be collected at specific sites of high emulsion because a surfactant was not used (to obtain a perfect emulsion). COD was considered as the most efficient technique to assess the removal oil because of its complex chemical content (hundreds to thousands of hydrocarbons ranging from $\mathrm{C}_{15}$ to $\mathrm{C}_{50}$, including a substantial fraction of nitrogen- and sulfur-containing compounds). ${ }^{49}$

\section{Results and Discussion}

\subsection{FT-IR Results}

The FT-IR spectra of composites (Fig. 1) and those of the start- ing materials were obtained to study possible changes in the chemical structure of the materials. Peaks were assigned according to the literature. Except for small shifts (due to the presence of inorganic elements in the structure of clinoptilolite), peaks of composites are the same as those of lignocellulose modified with siloxanes, because silicone is the main element in both the structures of clinoptilolite and siloxanes used for the preparation of the composites.

Therefore, the peak at $805 \mathrm{~cm}^{-1}$ was attributed to the symmetrical stretching of $\mathrm{AlO}_{4}$ of clinoptilolite or to the $\mathrm{Si}-\mathrm{C}$ bond present in the siloxane structure. ${ }^{50}$ The appearance of peaks between 1150 and $1068 \mathrm{~cm}^{-1}$ indicated the presence of a Si-O-Si bridge. But, these peaks may have overlapped with the presence of a $\mathrm{C}-\mathrm{O}$ bond. ${ }^{51}$ The peak at $1269 \mathrm{~cm}^{-1}$ was attributed to $\mathrm{Si}-\mathrm{CH}_{3}$ bond but also the negligible concentration of $\mathrm{C}-\mathrm{N}$ ( of C-NH${ }_{2}$ ) ending the siloxane. Peaks of small intensity observed at $1319 \mathrm{~cm}^{-1}$ and at $1407 \mathrm{~cm}^{-1}$ was assigned to the bending mode of $-\mathrm{CH}_{2}$ and $-\mathrm{CH}_{3}$ groups in the molecule. The peak at $1659 \mathrm{~cm}^{-1}$ was assigned to the carbonyl group. The peak at $2963 \mathrm{~cm}^{-1}$ was due to $\mathrm{C}-\mathrm{H}$ and $3458 \mathrm{~cm}^{-1}$ to $\mathrm{O}-\mathrm{H}$. Assignment of peaks was done as reported in the literature..$^{50-56}$

\subsection{XRD Analysis}

The XRD patterns of the composites (Fig. 2) were obtained to study the effect of lignocellulose and clinoptilolite modified with siloxane on the crystallinity of the composites. Comparison of the untreated grass with the composites shows the difference on the composites patterns. All the composites had their major peaks at around $2 \theta \approx 14.5^{\circ}, 22.1^{\circ}$ and $26.5^{\circ}$, which is quite different from untreated grass. XRD patterns showed changes in the intensity of peaks, likely due to the molecular weight of siloxanes and the scattering of clinoptilolite within the lignocellulosic.

The appearance of the broad peak around $14.5^{\circ}$ was attributed to the presence of clinoptilolite in the composites. Also, a minor shift from $21.2^{\circ}$ (untreated grass) to $22.1^{\circ}$ (composites) was observed and assigned to clinoptilolite..$^{57,58}$ In addition, the slightly increased peak intensity observed at $26.6^{\circ}$ could have been influenced by clinoptilolite which has a peak in those regions $\left(22^{\circ}\right.$ and $\left.\left.26^{\circ}\right)\right)^{57,58}$

\subsection{TGA of Lignocellulose-Clinoptilolite Composites}

The TGA thermograms of lignocellulose-clinoptilolite composites were used to study the thermal stability of composites. Plots (Fig. 3) showed materials having almost the same thermal stability profile. Differences in the slopes were only due to weight loss percentage with the first stage of mass loss around

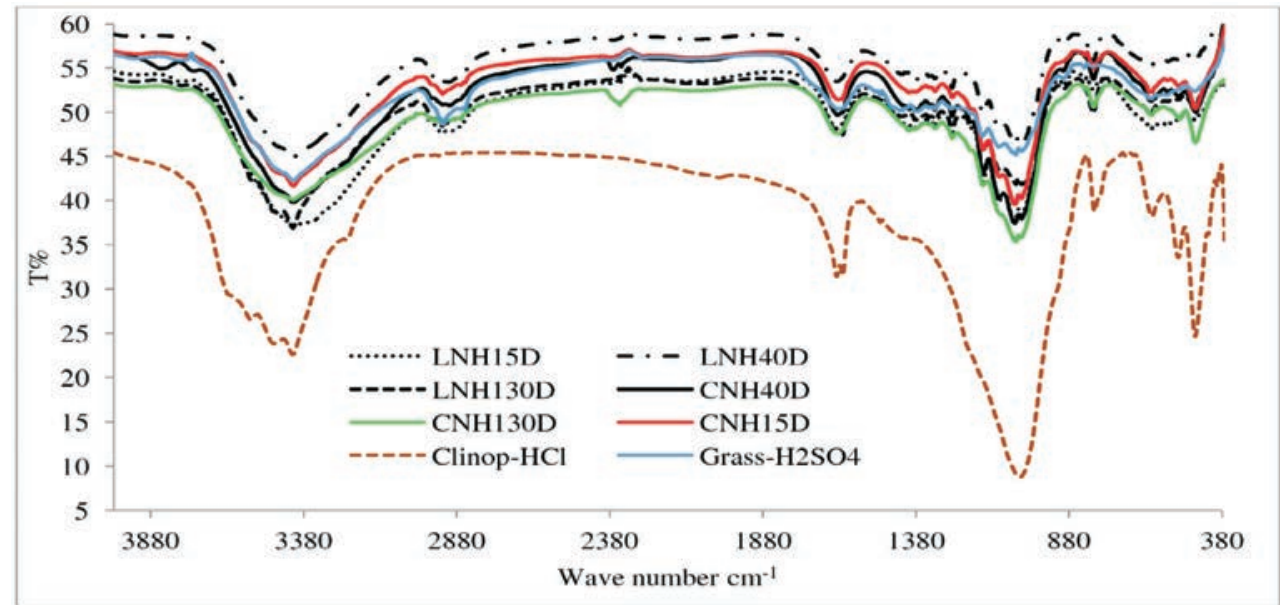

Figure 1 FT-IR of composites and starting materials. 


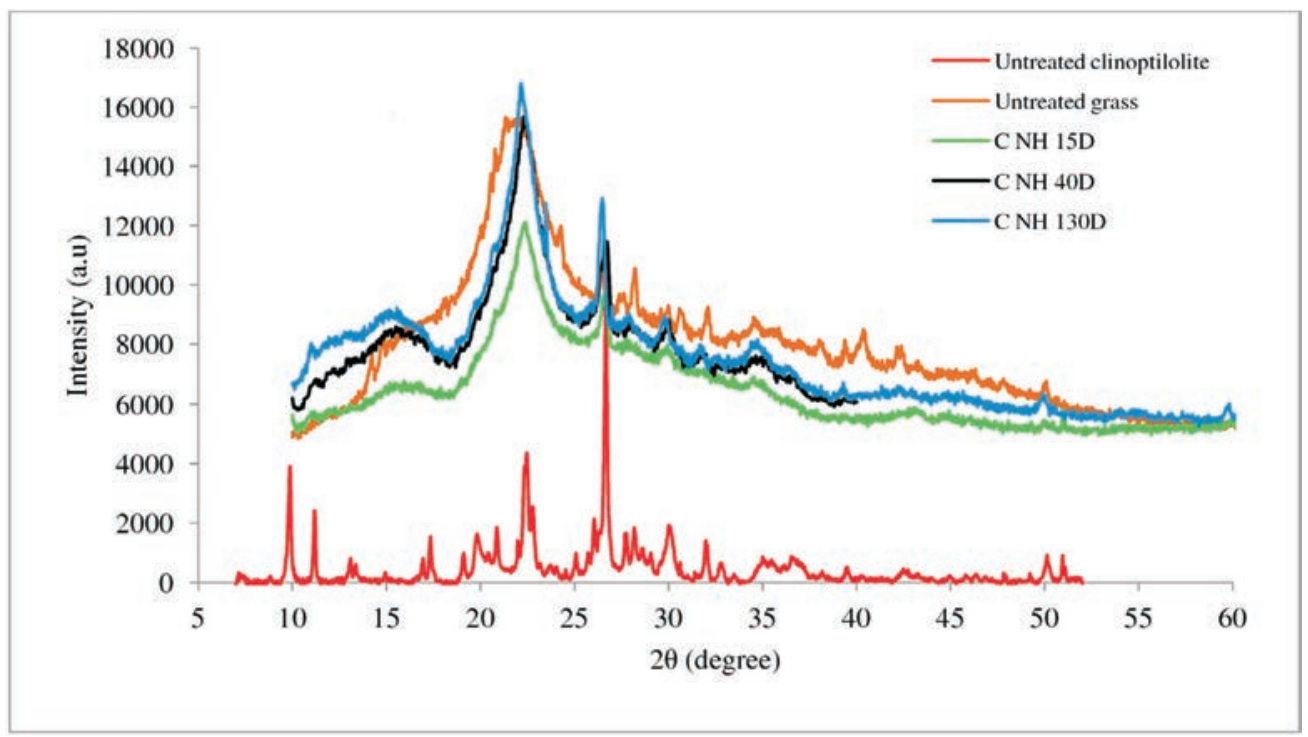

Figure 2 XRD patterns of composites, untreated grass and untreated clinoptilolite.

$75-76{ }^{\circ} \mathrm{C}$, ascribed to the water content of the composites.

The second mass loss (around $325^{\circ} \mathrm{C}$ for CNH15D, $352{ }^{\circ} \mathrm{C}$ for CNH40D and $332^{\circ} \mathrm{C}$ for $\mathrm{CNH} 130 \mathrm{D}$ ) was attributed to the volatile compounds formed during heating. The third but small weight loss (around $459^{\circ} \mathrm{C}$ for CNH15D, $484^{\circ} \mathrm{C}$ for CNH40D and $489^{\circ} \mathrm{C}$ for $\mathrm{CNH} 130 \mathrm{D})$ was probably due to the remaining persistent volatile compounds formed during heat exposure. It was noticed that composite CNH130D has less weight loss $(63 \%)$ than CNH15D (74 \%) and CNH40D (76 \%) suggesting that CNH130D was more thermally stable compared with the other two. The considerable amount of silicone in the structure of NH130D might have contributed to its high residual weight (NH15D: Mw = $1000 \mathrm{~g} \mathrm{~mol}^{-1}$; NH40D: $\mathrm{Mw}=2600 \mathrm{~g} \mathrm{~mol}^{-1}$; NH130D: $\mathrm{Mw}=$ $\left.11000 \mathrm{~g} \mathrm{~mol}^{-1}\right)$.

\subsection{SEM Analysis}

The dispersion of clinoptilolite in the lignocellulosic matrix of the composites was analyzed with SEM. The micrographs (Fig. 4) showed a complete dispersion of clinoptilolite within the lignocellulose matrix to the extent that it could hardly be distin-

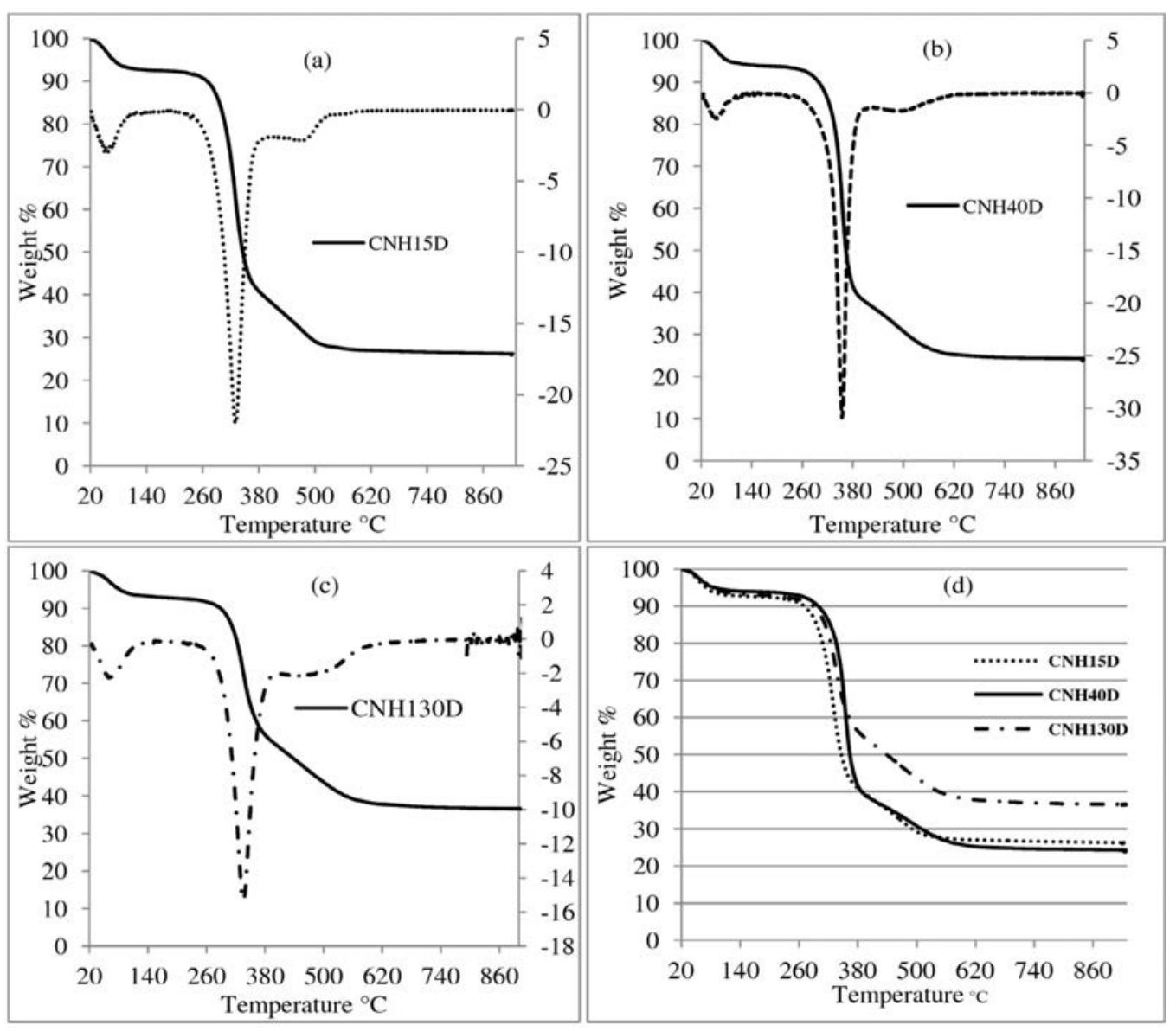

Figure 3 TGA and DTG of composites. 

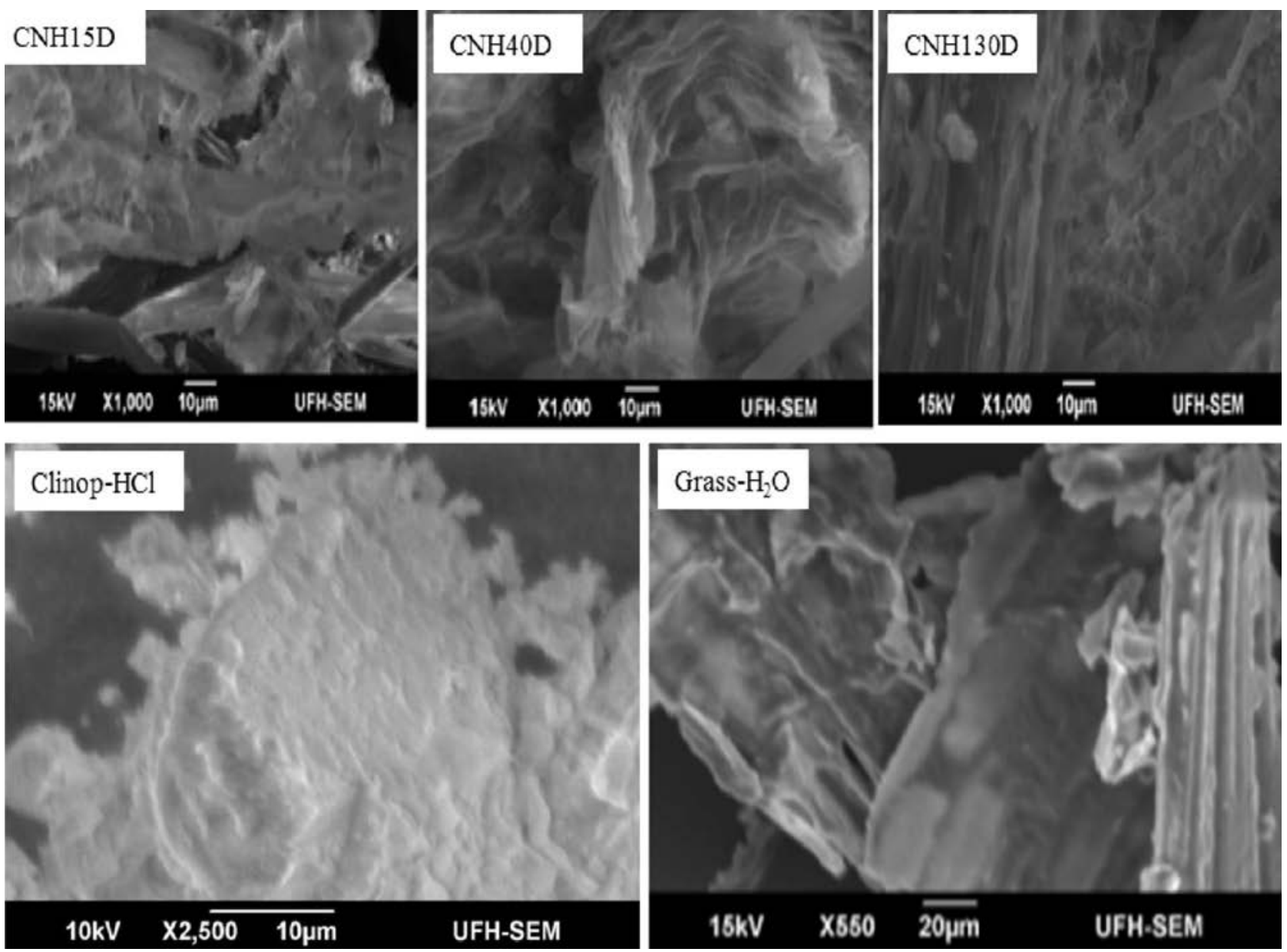

Figure 4 SEM of composites, clinoptilolite and grass.

guished from the other components. This dispersion of clinoptilolite suggested that siloxanes coupling agents played an important role between these two materials to a higher degree.

\subsection{Solid State NMR (SS NMR)}

Solid State NMR, a suitable technique for the inspection of the structure of hybrid materials, ${ }^{59}$ was used to characterize lignocellulose-clinoptilolite composite by means of ${ }^{13} \mathrm{C}$ and ${ }^{29} \mathrm{Si}$ nuclei. The aim of the investigation was to answer the following questions: (1) could the bond between lignocellulose and siloxane be an amide as reported by Gunanathan et al..$^{60}$ or an ether bond? (2) Can the Si of the repeat unit of the siloxane be distinguished

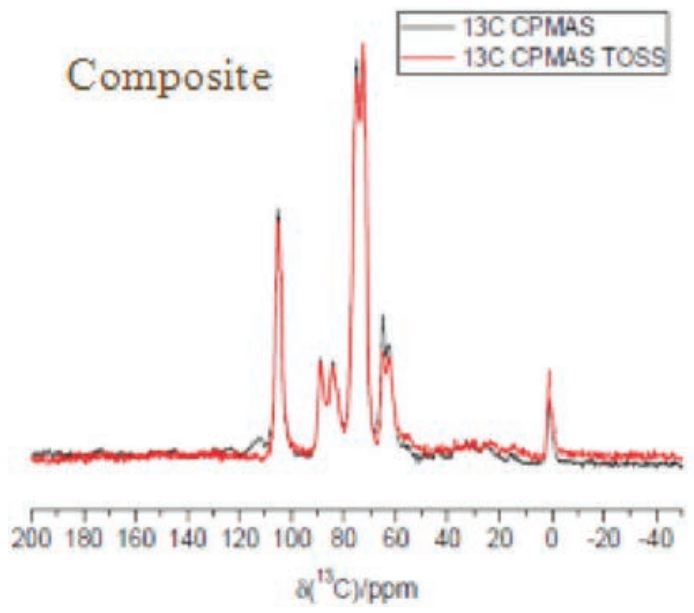

from 'end-standing' Si bonded to $\mathrm{CH}_{2}$ ? (3) Are the Si bonded or associated? (4) Was the composite formed via the formation of a chemical bond or via association? (5) Can the Si of clinoptilolite (clinop- $\mathrm{HCl}$ ) be distinguished from those of the siloxane?

\subsection{1. ${ }^{13} \mathrm{C}$ Solid State Results}

${ }^{13} \mathrm{C}$ NMR spectra (Fig. 5) shows the composite (CNH40D) and the lignocellulose (grass- $\mathrm{H}_{2} \mathrm{SO}_{4}$ ). By comparing the CPMAS with CPMAS TOSS spectra, the isotropic signals can be distinguished from spinning sidebands. Almost all signals that appeared in CPMAS also appeared in CPMAS TOSS spectra. Only the peak around 115 ppm could be identified as a spinning sideband.
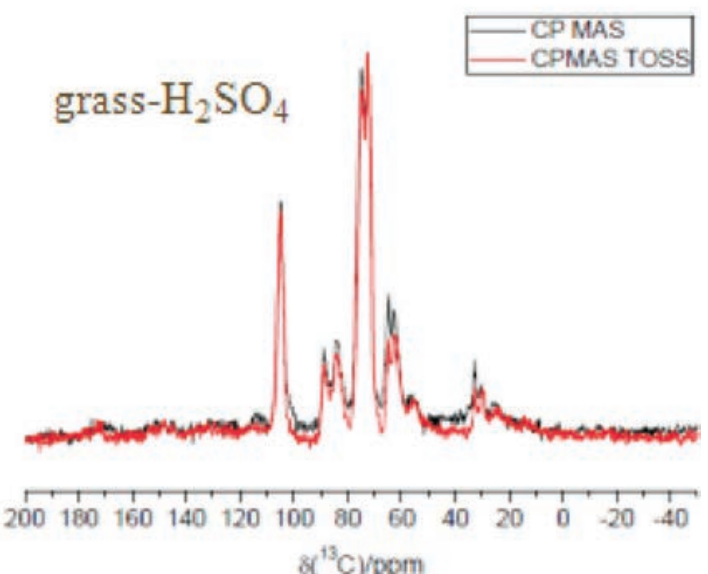

Figure 5 Comparison of ${ }^{13} \mathrm{C}\{1 \mathrm{H}\}$ CPMAS with CPMAS TOSS spectra of the composite (left) and grass- $\mathrm{H}_{2} \mathrm{SO}_{4}$ (right). 
The CPMAS spectra (Fig. 6) of the composite and grass- $\mathrm{H}_{2} \mathrm{SO}_{4}$ were compared; using the spectrum of grass- $\mathrm{H}_{2} \mathrm{SO}_{4}$ as a fingerprint spectrum, the lignocellulose components can be clearly identified in the composite. The spectra are very similar, but some differences can be observed: the spectrum of the composite shows an additional signal at $0 \mathrm{ppm}(1)$, which can be assigned to the methyl groups bonded to Si of the repeat unit of the siloxane in the composite. Signal (2) could possibly be a methylene signal of the coupling agent. As reported by Bardet ${ }^{61}$, the signal (4) at 62 ppm could be assigned to C of lignin and signal (3) to methoxy groups of lignin. The intensities of these signals were reduced in the composite compared to grass- $\mathrm{H}_{2} \mathrm{SO}_{4}$ indicating a structural change on the closest carbon of the composite.

It was noted that the signals (5) appearing at $32 \mathrm{ppm}$ were not observed in the spectrum of the composite. An assignment of this signal, however, was not possible as it could not be found in the literature dealing with SS NMR studies on lignocellulose. If signal (5) could be assigned to a component of lignocellulose and was not an impurity, its disappearance in the composite would suggest the formation of a chemically bonded composite rather than a composite formed by association of the components. The cellulose backbone structure was not largely affected by the formation of the composite as indicated by the very similar peak ratio of signal (6) representing crystalline (89 ppm) and amorphous C-4 (84 ppm) signals of cellulose. ${ }^{62-63}$

\subsection{2. ${ }^{29}$ Si SS NMR Results}

${ }^{29} \mathrm{Si}$ SS NMR results (Fig. 7) shows the ${ }^{29} \mathrm{Si}$ one-pulse MAS spectra of clinop- $\mathrm{HCl}$ measured with and without spinning sideband suppression. By comparison of the spectra of these different methods, the weak signals in the one-pulse MAS spectrum could be identified as spinning sidebands.When ${ }^{29} \mathrm{Si}$ SS NMR spectra of composite and clinop- $\mathrm{HCl}$ are compared, four different $\mathrm{Si}$ positions in clinop- $\mathrm{HCl}$ can be distinguished; they are labelled (1) to (4) (Fig. 8). Assignment of the position of the ${ }^{29} \mathrm{Si}$ in onepulse MASNMR spectrum (Table 2) was reported by Rivera. ${ }^{64}$

All positions were in the typical chemical shift range of $Q^{4}$ units. That means the observed Si atom was bonded to four bridging oxygens and was consequently part of a three-dimensional framework. The notation ' $(\mathrm{xAl})$ ' referred to the number of $\mathrm{Al}$ atoms in the second coordination sphere. For example ' $\mathrm{Q}^{4}(2 \mathrm{Al})^{\prime}$ indicated that the $\mathrm{Si}$ atom has two $\mathrm{Al}$ atoms and two Si atoms in its second coordination sphere bonded via bridging oxygen, respectively. Most of the clinop- $\mathrm{HCl}$ signals could be identified in the one-pulse MAS spectrum of the composite, too. Signal (4) could not be observed in the composite; however, this shoulder peak was too weak to be significant and could have been covered under the noise of the spectrum. As indicated (Table 3),

Table 2 Assignment of the position of the ${ }^{29} \mathrm{Si}$ in one-pulse MASNMR spectrum of clinop- $\mathrm{HCl}$.

\begin{tabular}{crc}
\hline Position & Chemical shift & Assignment $^{64}$ \\
\hline$(1)$ & $-112 \mathrm{ppm}$ & $\mathrm{Q}^{4}(0 \mathrm{Al})$ \\
$(2)$ & $-107 \mathrm{ppm}$ & $\mathrm{Q}^{4}(1 \mathrm{Al})$ \\
$(3)$ & $-100 \mathrm{ppm}$ & $\mathrm{Q}^{4}(1 \mathrm{Al})$ \\
$(4)$ & $-91 \mathrm{ppm}$ & $\mathrm{Q}^{4}(2 \mathrm{Al})$ \\
\hline
\end{tabular}

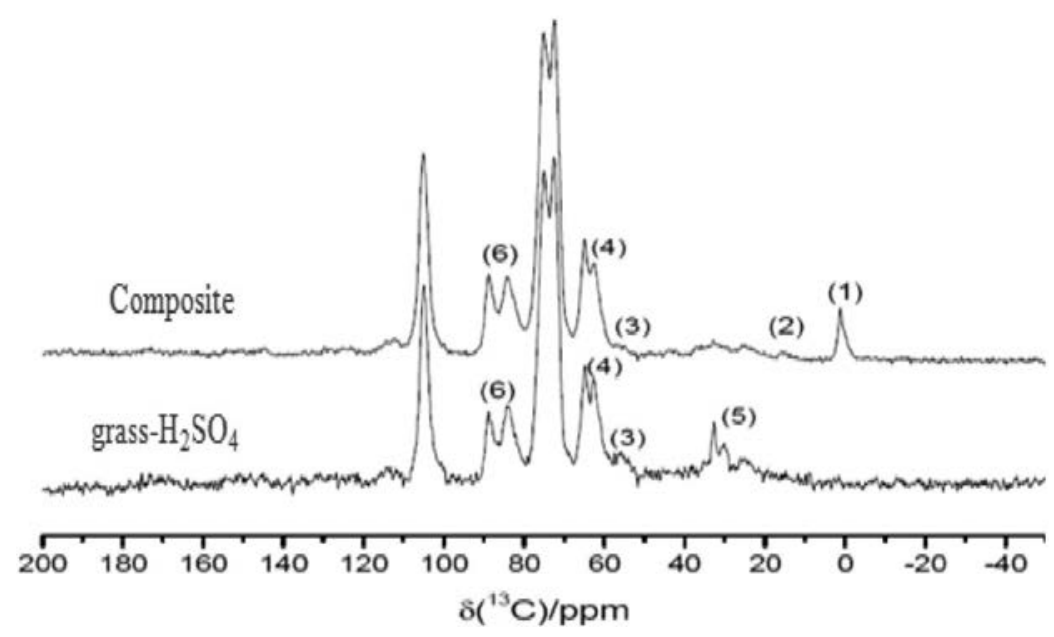

Figure $6{ }^{13} \mathrm{C}\{1 \mathrm{H}\}$ CPMAS spectra of $\mathrm{CNH} 40 \mathrm{D}$ and grass $-\mathrm{H}_{2} \mathrm{SO}_{4}$.

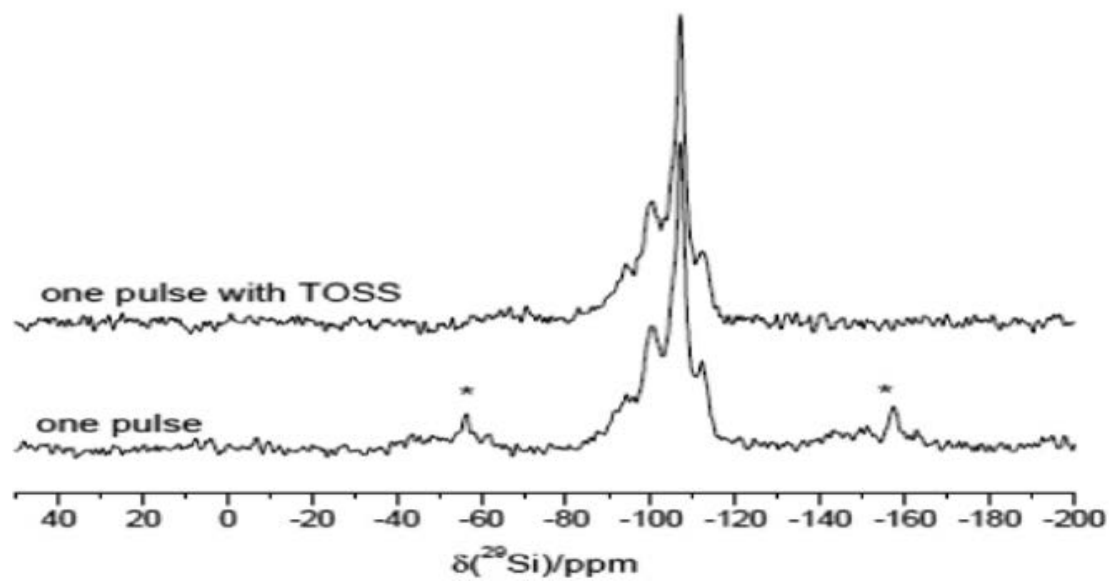

Figure $7{ }^{29} \mathrm{Si}$ one-pulse MAS spectra of clinop- $\mathrm{HCl}$ with (top) and without TOSS (bottom) (spinning sidebands are marked by an asterisk). 


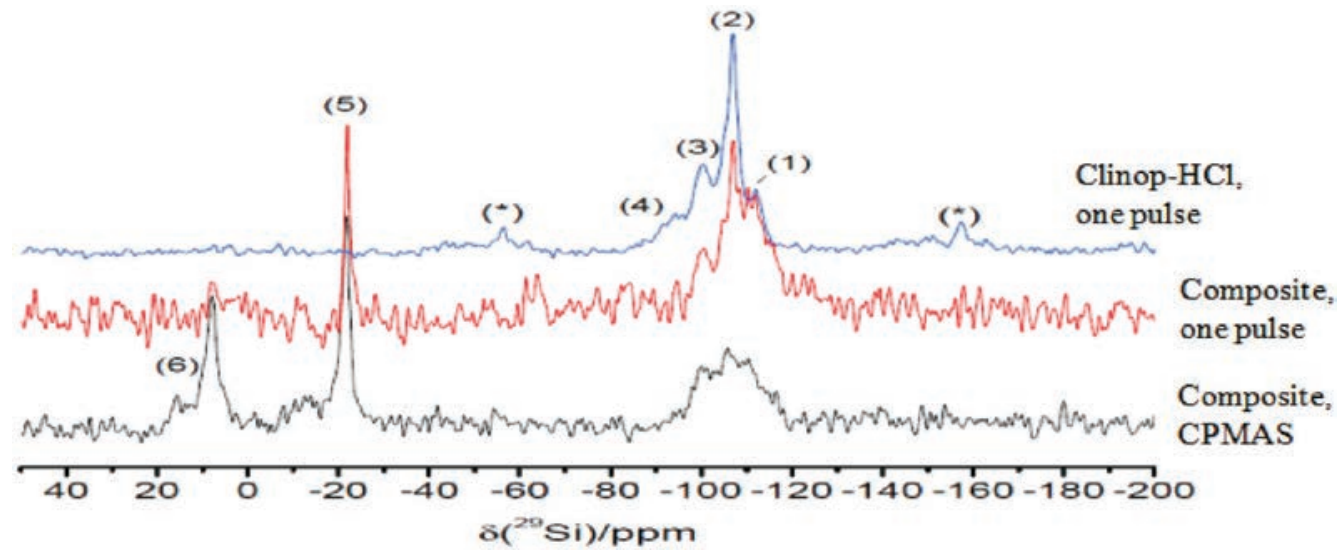

Figure 8 Comparison of ${ }^{29} \mathrm{Si} S \mathrm{SS}$ NMR spectra of clinop- $\mathrm{HCl}$ with the composite (the composite sample was measured using the method's onepulse MAS and CPMAS).

Table 3 Intensity ratios of the clinoptilolite position 1 and 3 relative to the most intense position 2 in clinop- $\mathrm{HCl}$ and the composite.

\begin{tabular}{lcc}
\hline Ratios & $\begin{array}{c}\text { Clinop-HCl } \\
\text { (one-pulse MAS) }\end{array}$ & $\begin{array}{c}\text { Composite } \\
\text { (one-pulse MAS) }\end{array}$ \\
\hline Int (1): Int (2) & 0.3 & 0.8 \\
Int (3): Int (2) & 0.4 & 0.6 \\
\hline
\end{tabular}

the intensity of signal (2) was notably reduced in the composite, implying that the $\mathrm{Si}$ atoms present as $\mathrm{Q}^{4}(1 \mathrm{Al})$ were affected by the formation of the composite.

The ${ }^{29} \mathrm{Si}$ one-pulse MAS spectrum displayed a clear signal (5) at-22 ppm, which could be assigned to Si of the repeat unit of the coupling agent, which was bonded to two methyl groups. Using the CPMAS technique, an additional peak (6) could be observed. Since its intensity was very large in the CPMAS compared to the one-pulse MAS, a close proximity to protons could thus be deduced. Therefore this signal could be assigned to the endstanding $\mathrm{Si}$ atoms in the coupling agent bonded to two methyl groups and one methylene group.

\subsection{Adsorption of Used Motor Oil}

\subsubsection{Kinetic of Adsorption}

An assessment of the effect of contact time and molecular weight of siloxanes on the adsorption of oil onto composites was conducted, and plots (Fig. 9) revealed that $10 \mathrm{~min}$ was enough to adsorb the maximum amount of COD during the process. CNH40D showed slightly higher adsorption properties at the beginning of the process than the other composites whereas, CNH130D (highest siloxane molecular weight) slightly desorbed the oil before they all reach equilibrium. This probably means that the molecular weight of siloxane moiety did not play a visible role during adsorption since the equilibrium is reached almost at the same time (180 $\mathrm{min})$ and with the same amount of adsorbate.

Data (Fig. 10) illustrated good compliance with the pseudosecond-order adsorption with correlation coefficients $\left(R^{2}\right)$ values above 0.999 , implying possible chemical interactions between adsorbate and adsorbent. ${ }^{63}$ The pseudo-first-order model, however, could not be applied in this case because of their very low correlation coefficients (some $R^{2}<0.1$ ).

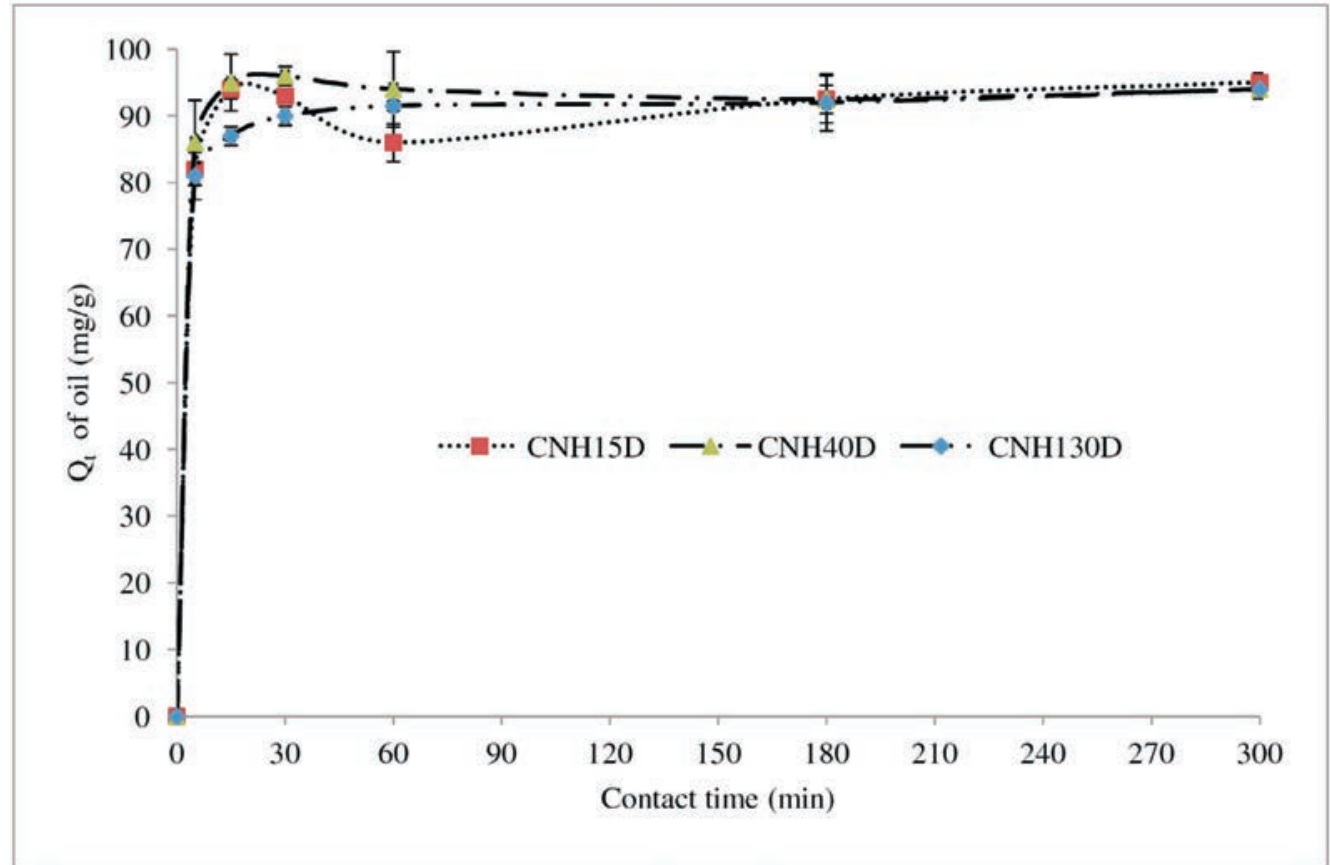

Figure 9 Effect of contact time and siloxanes molecular weight on the removal of oil by composites $(n=2)$. 


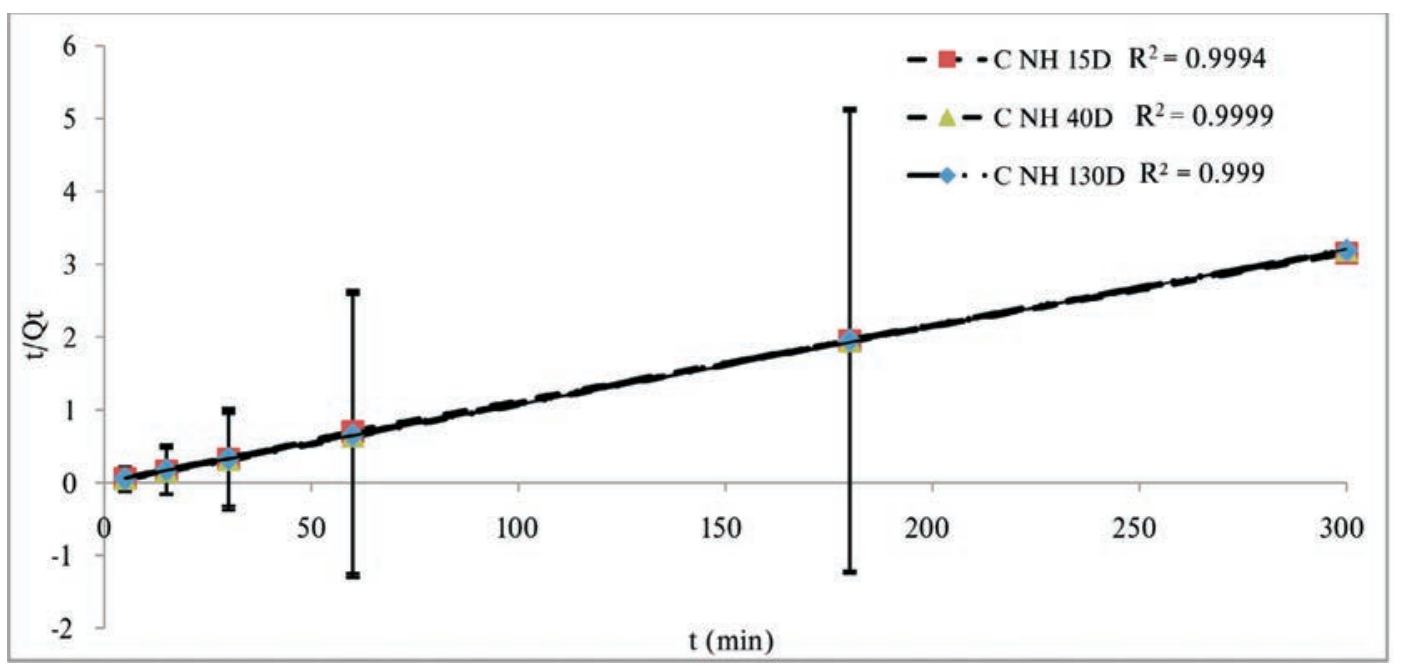

Figure 10 Pseudo-second-order of adsorption of oil onto composites (CNH15D, CNH40D and CNH130D) $(n=2)$.

\subsubsection{Isotherms of Adsorption}

Isotherms (Figs 11 and 12) of oil adsorbed onto the composites showed good $R^{2}$ values which permitted to suggest Langmuir model as the best fitting model when compared to the Freundlich model. The $R^{2}$ values of the Freundlich model, however, were not too low to be neglected, except for CNH130D $\left(R^{2}=0.4558\right)$. Therefore, based on isotherms, it is possible to assume that the surface of the adsorbent could be more complex than the monolayer structure suggested by the Langmuir model ${ }^{65-67}$ because of the complex nature of adsorbents (lignocellulose-siloxane-clinoptilolite).

\section{Conclusion}

In this study, we prepared lignocellulose-clinoptilolite composites by using $\mathrm{N}$-terminated siloxanes as a coupling agent between the two starting materials:grass- $\mathrm{H}_{2} \mathrm{SO}_{4}$ and clinop- $\mathrm{HCl}$. ${ }^{13} \mathrm{C}$ and ${ }^{29} \mathrm{Si}$ solid state NMR were used to explore the composite by comparing their spectra to those of the starting materials. It

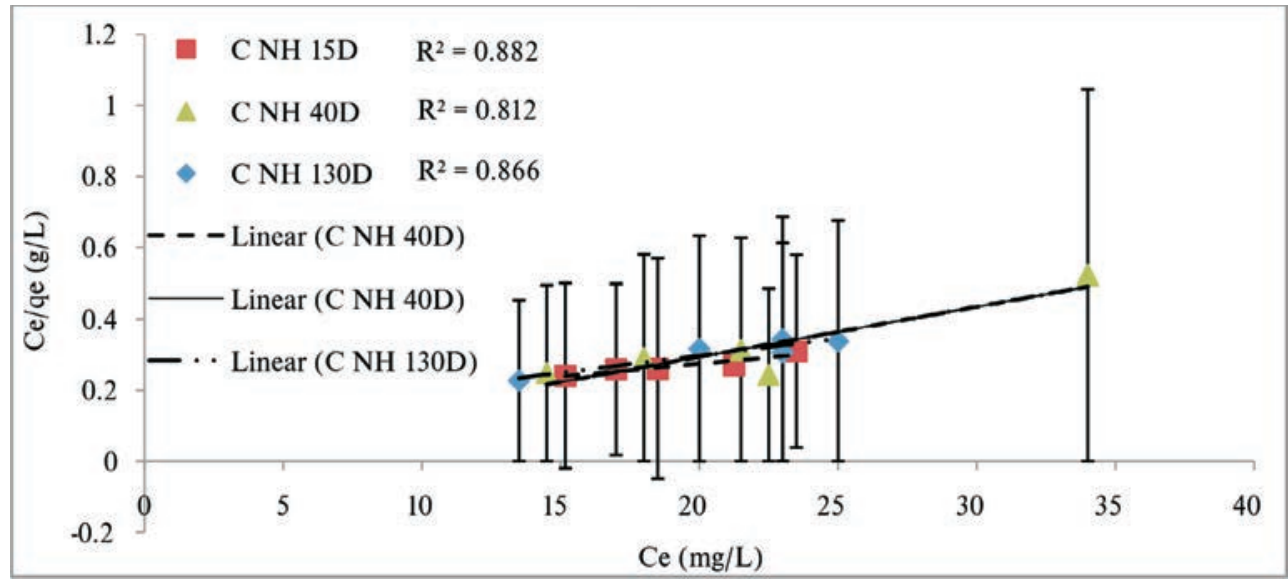

Figure 11 Langmuir isotherms of oil adsorbed onto composites (CNH15D, CNH40D and CNH130D) $(n=2)$.

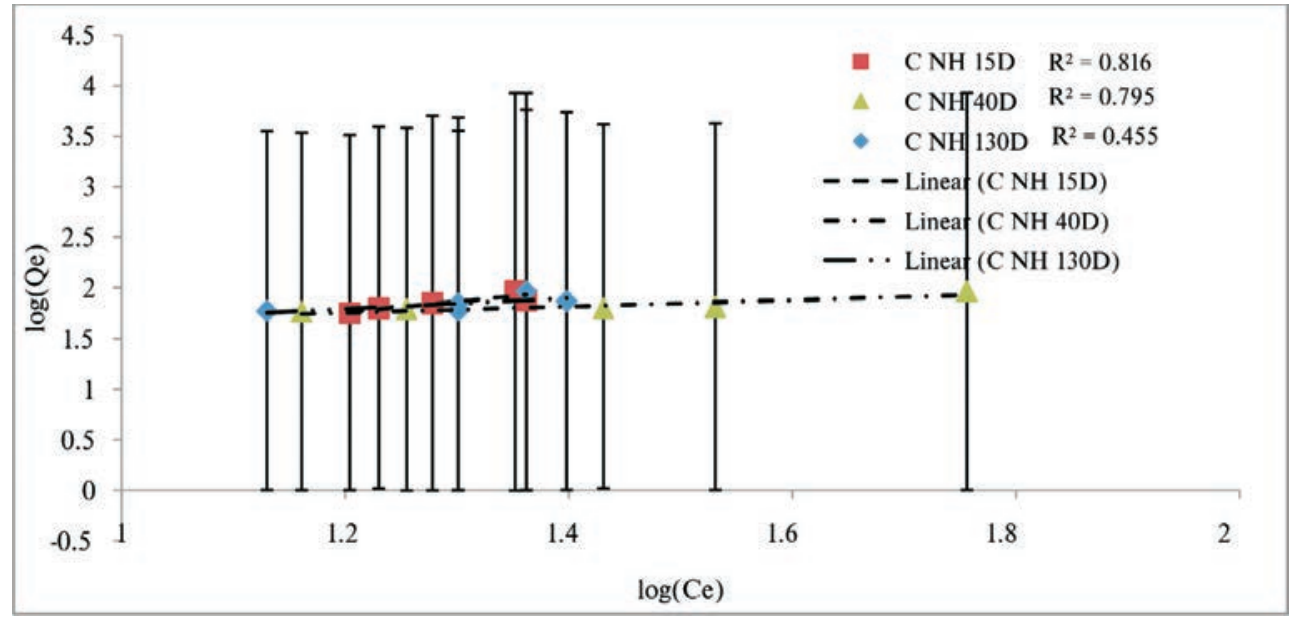

Figure 12 Freundlich isotherms of oil adsorbed onto composites (CNH15D, CNH40D and CNH130D) $(n=2)$. 
was possible to distinguish the carbon signals associated with grass- $\mathrm{H}_{2} \mathrm{SO}_{4}$ and the composite, and ${ }^{29} \mathrm{Si}$ signals associated with clinop- $\mathrm{HCl}$ and the composite. Other techniques (FT-IR, XRD, SEM, and TGA) were also used to explore the properties of the prepared composites. Furthermore, the prepared composites showed good adsorption properties by removing $92 \mathrm{mg} \mathrm{g}^{-1}$ of COD of oil.

\section{Acknowledgement}

Authors acknowledge the financial support received from Govan Mbeki Research \& Development Centre, University of Fort Hare, South Africa.

\section{References}

1 S.J. Eichhorn, C.A. Baillie, N. Zafeiropoulos, L.Y. Mwaikambo, M.P. Ansell, A. Dufresne, K.M. Entwistle, P.J. Herrera-Franco, G.C. Escamilla, L. Groom, M. Hughes, C. Hill, T.G. Rials and P.M. Wild Review: Current international research into cellulosic fibres and composites, J. Mater. Sci., 2001, 36, 2107 - 2131.

2 L Avérous and N. Boquillon, Biocomposites based on plasticised starch: thermal and mechanical behaviours, Carbohyd. Polym., 2004, 56(2), 111-122.

3 M.J. John, R.D. Anandjiwala, L.A. Pothan and S. Thomas, Cellulosic fibre-reinforced green composites, Compos. Interface, 2007, 14(7-9), 733-751.

4 M.J. John and S. Thomas, Review: Biofibres and biocomposites, Carbohyd. Polym, 2008, 71, 343-364.

5 T. Nishino and N. Arimoto, All-Cellulose Composite Prepared by Selective Dissolving of Fiber Surface, Biomacromolecules, 2007, 8 , 2712-2716.

6 C.J. Brinker and G.W. Scherer, Sol-Gel Science: The Physics and Chemistry of Sol-Gel Processing, Academic Press, San Diego, California, USA, 1990.

7 J.M. Duval, A.J.B. Kemperman, B. Folkers, M.H.V. Mulder, G. Desgrandchamps and C.A. Smolders, Preparation of zeolite filled glassy polymer membranes, J. Appl. Polym. Sci., 1994, 54, 409-418.

8 N. Soykeabkaew, N. Arimoto, T. Nishino, T. Peijs, All-cellulose composites by surface selective dissolution of aligned ligno-cellulosic fibres, Compos. Sci. Technol., 2008, 68, 2201-2207.

9 H.L. Bos, J. Mussig and M.J.A. Van den Oever, Mechanical properties of short-flax-fibre reinforced compounds, Composites: Part A, 2006, 37(10), 1591-1604.

10 A. Gomes, T. Matsuo, K. Goda and J. Ohgi, Development and effect of alkali treatment on tensile properties of curaua fiber green composites, Compos. Part A-Appl S, 2007, 38(8), 1811-1820.

11 X. Li, L.G. Tabil and S.J. Panigrahi, Chemical treatments of natural fiber for use in natural fiber-reinforced composites: a review, Polym. Environ., 2007, 15(1), 25-33.

12 O.Y. Mansour Lignocellulose-polymer composite III, J. Appl. Polym. Sci., 1993, 47(5), 839-846.

13 S.M. Serino, A.L. Garofalo, M.N. Goeser and M.J. Deaner, Polymer covered advanced polymer/wood composite structural member, US Pat. 6357197 (2002).

14 Z. Lin and S. Renneckar, Nanocomposite-based lignocellulosicfibers 2: Layer-by-layer modification of wood fibers for reinforcement in thermoplastic composites, Composites: Part A, 2011, 42, 84-91.

$15 \mathrm{~T}$. Bunhu and L. Tichagwa, Adsorption of methyl orange, $\mathrm{Pb}^{2+}$ and $\mathrm{Cd}^{2+}$ from aqueous solution by composites of lignocellulosemontmorillonite modified with methacryloxypropyl trimethoxysilane, Macromol. Symp., 2012, 313-314, 146-156.

16 E.D. Fisher, W. Wypart and Kristofferson Marcus, Wood-polymerzeolite composites, US Pat. N US 7,550,404 B2 (2009).

17 L.I. Bel' chinskaya, Strel'nikova O. Yu, L.A. Novikova, F. Ressner and O.V. Voishcheva, Enhancement of the adsorption selectivity of nanoporous clinoptilolite by hydrophobization with organosiloxanes, Prot Met+, 2008, 44(4), 390-393.

18 A. Zampieri, S. Kullmann, T. Selvam, J. Bauer, W. Schwieger, H. Sieber, T. Fey, and P. Greil, Bioinspired rattan-derived SiSiC/Zeolite monoliths: preparation and characterization, Micropor. Mesopor. Mat., 2006, 90(1-3), 162-174
19 S. Mintova and V. Valtchev, Preparation of zeolite-covered cellulose fibers, Abstract of Papers, 209th ACS National Meeting, A.C.S. (1995).

$20 \mathrm{~J}$. Troquet, C. Larroche and C.G. Dussap, Evidence for the occurrence of an oxygen limitation during soil bioremediation by solid-state fermentation, Biochem. Eng. J., 2003, 13, 103-112.

21 B. Antizar-Ladislao, J. Lopez-Real and A.J. Beck, Laboratory studies of the remediation of polycyclic aromatic hydrocarbon contaminated soil by invessel composting, Waste Manag., 2005, 25, 281-289.

22 B. Antizar-Ladislao, J. Lopez-Real and A.J. Beck, Degradation of polycyclic aromatic hydrocarbons (PAHs) in an aged coal-tar contaminated soil under in-vessel composting conditions, Environ. Pollut., 2006, 141, 459-468.

23 R. Vazquez-Duhalt, Environmental impact of used motor oil: review, Sci. Total Environ., 1989, 79(1), 1-23.

24 E. Clonfero, B. Nardini, M. Marchioro, A. Bordin and G. Gabbani, Mutagenicity and contents of polycyclic aromatic hydrocarbons in used and recycled motor oils, Mutat. Res-Genet. Tox., 1996, 368(3-4), 283-291.

25 M. Granella, C. Ballarin, B. Nardini, M. Marchioro and E. Clonfero, Mutagenicity and contents of polycyclic aromatic hydrocarbons in new high-viscosity naphthenic oils and used and recycled mineral oils, Mutat. Res., 1995, 343, 145-150.

26 J.F. Nash, S.D. Gettings, W. Diembeck, M. Chudowski and A.L. Kraus, A toxicological review of topical exposure to white mineral oils, $F d$. Chem. Toxic., 1996, 34(2) 213-225.

27 I.N.E. Onwurah, V.N. Ogugua, N.B. Onyike, A.E. Ochonogor and O.F.Otitoju, Crude oil spills in the environment, effects and some innovative clean-up biotechnologies, IJER, 2007, 1(4), 307-320.

28 H. Lefcort, K.A. Hancock, K.M. Maur and D.C. Rostal, The effects of used motor oil, silt, and the water mold Saprolegnia parasitica on the growth and survival of mole salamanders (genus Ambystoma), Arch. Environ. Contam. Toxicol., 1997, 32, 383-388.

29 R.F. Johnson and T.G. Manjrekar, Removal of oil from water surfaces by sorption on unstructured fibers, Environ. Sci. Technol., 1973, 7, 439-443.

30 Ch. Teas, S. Kalligeros, F. Zanikos, S. Stournas, E. Lois and G. Anastopoulos, Investigation of the effectiveness of absorbent materials in oil spill clean up, Desalination, 2001, 140, 259-264.

31 Q.F. Wei, R.R. Mather, A.F. Fotheringham and R.D. Yang, Evaluation of nonwoven polypropylene oil sorbents in marine oil-spill recovery, Mar. Pollut. Bull., 2003, 46, 780-783.

32 S.A. Sayed and A.M. Zayed, Investigation of the effectiveness of some adsorbent materials in oil spill clean-ups, Desalination, 2006, 194, 90100.

33 A. Gammoun, S. Tahiri, A. Albizane, M. Azzi, J. Moros, S. Garrigues and M. de la Guardia, Separation of motor oils, oily wastes and hydrocarbons from contaminated water by sorption on chrome shavings, J. Hazard. Mater., 2007, 145, 148-153.

34 V. Rajaković-Ognjanović, G. Aleksić and L. Rajaković, Governing factors for motor oil removal from water with different sorption materials, J. Hazard. Mater., 2008, 154(1-3), 558-563.

35 H. Moriwaki, S. Kitajima, M. Kurashima, A. Hagiwara, K. Haraguchi, K. Shirai, R. Kanekatsu and K. Kiguchi, Utilization of silkworm cocoon waste as a sorbent for the removal of oil from water, J. Hazard. Mater., 2009, 165, 266-270.

36 R.M. Barrer and M.B. Makki, Molecular sieve sorbents from clinoptilolite, Can. J. Chem.,1964, 2, 1481-1487.

37 M.P. Elizalde-González, J. Mattusch, R. Wennrich and P. Morgenstern, Uptake of arsenite and arsenate by clinoptilolite-rich tuffs, Micropor. Mesopor. Mat., 2001, 46(2-3), 277-286.

38 A. Top and S. Ülkü, Silver, zinc, and copper exchange in a Na-clinoptilolite and resulting effect on antibacterial activity, Appl. Clay Sci. 2004, 27(1-2), 13-19.

39 H. Faghihian and M. Pirouzi, Cis/trans-but-2-ene adsorption on natural and modified clinoptilolite, Clay Minerals,2009, 44, 405-409.

40 R. Ruiz and T. Ehrman, Dilute acid hydrolysis procedure for determination of total sugars in the liquid fraction of process samples, in Chemical Analysis and Testing Task Laboratory Analytical Procedure, LAP-014, Department of Energy, Washington, 1996.

41 L. Palmowski and J. Muller, Influence of the size reduction of organic waste on their anaerobic digestion, in II International Symposium on Anaerobic Digestion of Solid Waste, Barcelona, 1999, 15-17, 137-144. 
42 H. Shibazaki, S. Kuga, F. Onabe and R.M. Brown Jr, Acid hydrolysis behaviour of microbial cellulose II, Polymer, 1995, 36(26), 4971-4916.

43 N. Curreli, M. Agelli, B. Pisu, A. Rescigno, E. Sanjust and A. Rinaldi, Complete and efficient enzymatic hydrolysis of pretreated wheat straw, Process. Biochem., 2002, 37, 937-941.

44 Q. Xiang, Y.Y. Lee, P.O. Pettersson and R.W. Torget, Heterogeneous aspects of acid hydrolysis of $\alpha$-cellulose', Appl. Biochem. Biotech., 2003, 107(1-3), 505-514.

45 F. Hong and K. Qiu, An alternative carbon source from konjac powder for enhancing production of bacterial cellulose in static cultures by a model strain Acetobacter aceti subsp. xylinus ATCC 23770, Carbohyd. Polym, 2008, 72, 545-549.

46 M.C. Matías, M.U. De La Orden, C. González Sánchez and J. Martínez Urreaga, Comparative spectroscopic study of the modification of cellulosic materials with different coupling agents, J. Appl. Polym. Sci., 2000, 75, 256-266.

47 F. Le Digabel, N. Boquillon, P. Dole, B. Monties and L. Averous, Properties of thermoplastic composites based on wheat-straw lignocellulosic fillers, J. Appl. Polym. Sci., 2004, 93(1), 428-436.

48 F. Cao, P. Bai, H. Li, Y. Ma, X. Deng and C. Zhao, Preparation of polyethersulfone-organophilic montmorillonite hybrid particles for the removal of bisphenol A, J. Hazard. Mater., 2009, 162, 791-798.

49 ABB-Environmental, Compilation of data on the composition, physical characteristics and water solubility of fuel products, Prepared for Massachusetts Department of Environmental Protection, Wakefield, Massachusetts, 1990.

50 H. Faghihian, M. Talebi and M. Pirouzi, Adsorption of nitrogen from natural gas by clinoptilolite, J. Iran. Chem. Soc., 2008, 5(3), 394-399.

$51 \mathrm{~J}$. Coates, Interpretation of infrared spectra: a practical approach, in Encyclopaedia of Analytical Chemistry, (R.A. Meyers, ed.), John Wiley \& Sons, New York, NY, USA, 2000, pp. 10815-10837.

52 D.W. Brown, A.J. Floyd and M. Sainsbury, Organic Spectroscopy, John Willey \& Sons, New York, NY, USA,1988.

53 W. Kemp, Organic spectroscopy, 3rd edn, ELBBS \& McMillan, City, UK, 1991.

54 H. Homma, T. Kuroyagi, K. Izumi, C.L. Mirley, J. Ronzello and S.A. Boggs, Diffusion of low molecular weight siloxane from bulk to surface, IEEET Dielect El In, 1999, 6(3), 370-375.
55 E. Hamciuc, C. Hamciuc and M. Cazacu, Poly(1,3,4-oxadiazoleether-imide)s and their polydimethylsiloxane-containing copolymers, Eur. Polym. J., 2007, 43, 4739-4749.

56 B. Mohebby and R.Hadjihassani, Moisture repellent effect of acetylation on poplar fibres, J. Agric. Sci. Technol., 2008, 10, 157-163.

57 G.M. Arifuzzaman Khan, S.M.Y. Arafat, M.N. Reza, S.M. Abdur Razzaque \& Md. Shamsul Alam, Linde Type-A zeolite synthesis and effect of crystallization on its surface acidity, Indian J. Chem. Technol., 2010, 17, 303-308.

58 A.A. Kittur,M.Y. Kariduraganavar, U.S. Toti, K. Ramesh,T.M. Aminabhavi, Pervaporation Separation of Water-Isopropanol Mixtures Using ZSM-5 Zeolite Incorporated Poly(vinyl alcohol) Membranes, J. Appl. Polym. Sci., 2003, 90(9), 2441-2448.

59 T. Takayama, Inorganic polymers, in Solid State NMR of Polymers, (I. Ando and T. Asakura, eds.), Elsevier, Amsterdam, 1998.

60 C. Gunanathan, Y. Ben-David and D. Milstein, Direct synthesis of amides from alcohols and amines with liberation of $\mathrm{H}_{2}$, Science, 2007, 317(5839), 790-792.

61 M. Bardet, M.F. Foray and Q.K. Trân, High-resolution solid-state CPMAS NMR study of archaeological woods, Anal. Chem., 2002, 74, 4386-5390.

62 T. Liitiä, S.L. Maunu and B. Hortling, Solid state NMR studies on cellulose crystallinity in fines and bulk fibres separated from refined kraft pulp, Holzforschung, 2000, 54, 618-624.

63 R.H. Newman and J.A. Hemmingson, Determination of the degree of cellulose crystallinity in wood by carbon- 13 nuclear magnetic resonance spectroscopy, Holzforschung, 1990, 44, 351-355.

64 A. Rivera, T. Farías, A.R. Ruiz-Salvador and L.C. de Ménorval, Preliminary characterization of drug support systems based on natural clinoptilolite, Micropor. Mesopor. Mat., 2003, 61, 249-259.

65 Y.S. Ho and G. McKay, Pseudo-second order model for sorption processes, Process Biochem., 1999, 34, 451-465.

66 M.D. Levant and T. Vermeulen, Binary Langmuir and Freundlich isotherms for ideal adsorbed solutions, J. Phys. Chem., 1981, 85, 3247-3250.

67 K.S.W. Sing, D.H. Everett, R.A.W. Haul, L. Moscou, R.A. Pierotti, J. Rouquerol and T. Siemiewska, Reporting physisorption data for Gas/solid systems with special reference to the determination of surface area and porosity, Pure App. Chem., 1985, 57(4), 603-619. 